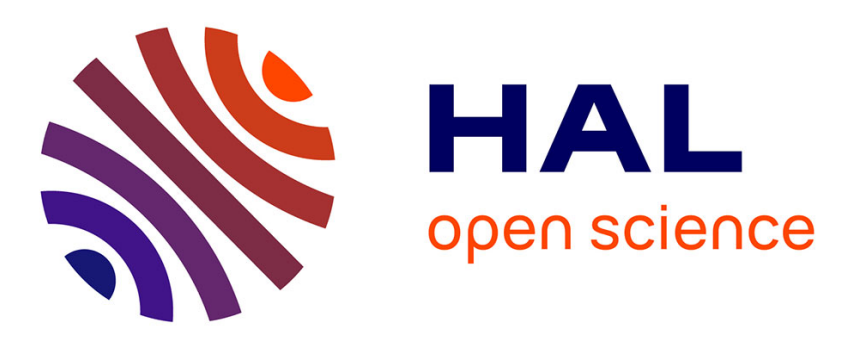

\title{
Nonlinear numerical method for earthquake site response analysis I - elastoplastic cyclic model and parameter identification strategy
}

Fernando Lopez-Caballero, Arézou Modaressi-Farahmand-Razavi, Hormoz Modaressi

\section{To cite this version:}

Fernando Lopez-Caballero, Arézou Modaressi-Farahmand-Razavi, Hormoz Modaressi. Nonlinear numerical method for earthquake site response analysis I - elastoplastic cyclic model and parameter identification strategy. Bulletin of Earthquake Engineering, 2007, 5 (3), pp.303-323. 10.1007/s10518007-9032-7 . hal-00179375

\section{HAL Id: hal-00179375 \\ https://hal.science/hal-00179375}

Submitted on 18 Mar 2008

HAL is a multi-disciplinary open access archive for the deposit and dissemination of scientific research documents, whether they are published or not. The documents may come from teaching and research institutions in France or abroad, or from public or private research centers.
L'archive ouverte pluridisciplinaire HAL, est destinée au dépôt et à la diffusion de documents scientifiques de niveau recherche, publiés ou non, émanant des établissements d'enseignement et de recherche français ou étrangers, des laboratoires publics ou privés. 


\title{
Nonlinear numerical method for earthquake site response analysis I- elastoplastic cyclic model \& parameter identification strategy
}

\author{
Fernando Lopez-Caballero and Arezou Modaressi \\ Laboratoire MSS-Mat CNRS UMR 8579,Ecole Centrale Paris, Grande Voie des \\ Vignes, 92295 Châtenay-Malabry Cedex, France \\ Hormoz Modaressi \\ Development Planning and Natural Risks Department, BRGM, BP 6009,45060 \\ Orléans Cedex 2, France
}

\begin{abstract}
This paper, along with its companion paper, presents the importance of the adequate soil behaviour model to simulate earthquake site response analysis. An elastoplastic model taking into account the elementary necessary plastic mechanisms such as progressive friction mobilization, Coulomb type failure, critical state and dilatancy/contractance flow rule, is used. However, one of the obstacles in the use of elastoplastic models in the everyday design processes for evaluation of the seismic soil response is the difficulty in identifying their parameters. In this paper, a methodology to identify a coherent set of parameters of the elastoplastic model for a given type of soil is presented. The strategy behind the decision making process proposed here is based on the use of minimum physical and easily measurable properties of the soil to directly provide or indirectly assess the required model parameters.
\end{abstract}

Keywords: Constitutive model; Cyclic Loading; Elastoplastic; Parameter identification; Liquefaction

\section{Introduction}

To simulate numerically seismic soil response, two approaches can be considered: the equivalent-linear approach and a truly non-linear elastoplastic modeling. The variation of shear modulus and material damping ratio with shear strain, known as $G-\gamma$ and $D-\gamma$ curves, has been known to be a significant feature of the soil behaviour submitted to cyclic loading since the pioneer works by Seed and Idriss (1970). This observation resulted in the equivalent-linear approach that has been extensively used since then. Even though its shortcomings have been repeatedly enumerated in the past, it has become the major tool in practical engineering applications due to its simplicity. On the other hand, the emergence of cyclic elastoplastic constitutive models for soils in the late 70's and early 80's has opened a new horizon for soil dynamics studies, (e.g. Prévost and Hoeg, 1975; Ghaboussi and Dikmen, 1978; Aubry et al., 1982 among others).

(c) 2006 Kluwer Academic Publishers. Printed in the Netherlands. 
The information concerning the capability of these models in representing the variation of the shear modulus and the damping ratio in a wide range of shear strain, namely from $10^{-6}$ to $10^{-2}$ is scarce. Pande and Pietruszczak (1986) compared several constitutive models and reported that almost all of them, except those based directly on this property, were inefficient in reproducing this feature of soil behaviour. In this paper, we will give some numerical results showing that it is possible to simulate realistic $G-\gamma$ and $D-\gamma$ curves using an elastoplastic model.

The use of models based on the elastoplasticity theory is more suitable than equivalent-linear approach as they represent a rational mechanical process. In this kind of model, parameters should be chosen so that they are closely related to the rheology that describes the material properties at various strain levels. In some cases these rheological models do not necessarily have physical parameters. Sometimes there are indirect parameters that cannot be measured in the laboratory.

Thus, one of the obstacles in using such models is the difficulty in identifying their parameters. In addition, the lack of knowledge of soil properties is common in seismic studies and unfortunately, the cost of laboratory and in-situ tests is quite expensive, so a complete geotechnical description of a site is very rare.

The elastoplastic model implemented in CyberQuake (Modaressi and Foerster, 2000) is used here and a methodology to identify the model parameters with a minimum laboratory data is proposed. This model is a derivation of the ECP elastoplastic models (also known as Hujeux's model) developed, refined and enhanced by Aubry and co-workers since the early 80's (Aubry et al. (1982), Hujeux (1985) for the 3D cyclic behaviour, Aubry et al. (1990) for the interface behaviour). Mellal (1997) integrated and used the present model for seismic site effects studies.

The strategy developed in this paper is based on the extensive work of the authors in this field and it can be generalized to all of the ECP family models. It is based on the use of easily measurable soil properties. The model's parameter identification methodology is developed for both clays and sands. As the $G-\gamma$ and $D-\gamma$ curves are largely used for the material identification in seismic analyses, we focus our work on such results. Thus, the objective of the soil identification is to obtain the elastoplastic model parameters resulting in a given set of $G-\gamma$ and $D-\gamma$ curves measured in a shear test. 


\section{Formulation of the elastoplastic constitutive model}

The cyclic CyberQuake model is written for laterally infinite parallel soil layers, where a one-dimensional geometry can be considered. However, the three dimensional kinematics assumptions integrate the complete displacement field. If $x, y$ and $z$ represent the reference axes in which the seismic motion is described, with $z$ perpendicular to the soil layers, the three displacement components will vary only with respect to the $z$ axis if:

$$
\underline{u}(z)=\underline{u}_{x}(z)+\underline{u}_{y}(z)+\underline{u}_{z}(z)
$$

where $\underline{u}_{i}$ represents the component of the displacement along $i$ direction.

On the potential shear plane with normal vector $\underline{n}$, the displacement can be presented as :

$$
\underline{u}(z)=\underline{u}_{t}(z)+u_{n}(z) \cdot \underline{n}
$$

where $\underline{u}_{t}$ designates the resultant of the displacements on the plane which defines the shear direction. Thus, the shear $(\underline{\gamma})$ and the normal $(\varepsilon)$ strains are :

$$
\begin{aligned}
& \underline{\gamma}(z)=\frac{\partial \underline{u}_{t}}{\partial z}=\frac{\partial \underline{u}_{x}}{\partial z}+\frac{\partial \underline{u}_{y}}{\partial z} \\
& \varepsilon(z)=\frac{\partial u_{n}}{\partial z}
\end{aligned}
$$

In fact, the simple geometry consideration is usually an inherent feature of simplified methods. The principal step for simplified models is to introduce important aspects of the soil behaviour, such as strain shearing and/or pore-pressure build-up induced by the cyclic loading during earthquakes. Moreover, the seismic motion in the multilayer system is adequately represented considering a plane plastic shear mechanism.

The saturated soil skeleton is considered as a mixture of solid grains and the interstitial water. The behaviour of the solid skeleton is derived assuming the principle of effective stress as proposed by Terzaghi, where the total stress tensor $(\underline{\underline{\sigma}})$ is split in two components: the effective stress tensor $\left(\underline{\underline{\sigma}}^{\prime}\right)$ and the pore pressure $(p)$. Where $\underline{\underline{\sigma}}=\underline{\underline{\sigma^{\prime}}}-p \cdot \underline{\underline{I}}$ with $\underline{\underline{I}}$ the identity second order tensor. In this paper the mechanics of continuous media sign convention is adopted (i.e. compression negative).

This principle is valid as far as the solid grain compressibility is much smaller than the compressibility of the solid skeleton. We also assume that the pore pressure variation does not induce any deformation of the grains. 
The effective stress (respectively strain) vector can be decomposed into normal and tangential components: $\sigma^{\prime}$ (respect. $\varepsilon$ ) and $\underline{\tau}$ (respect. $\underline{\gamma}$.

Modeling the elastic behaviour In the very small strain range, soil behaviour is reversible. However, the elastic properties of the soil depend on the stress state. Assuming an isotropic elastic behaviour, the effective stress and strain rates are related as follows:

$$
\left\{\begin{aligned}
\dot{\sigma}^{\prime} & =E^{*}\left(\underline{\underline{\sigma}}^{\prime}\right) \dot{\varepsilon}^{e} \\
\dot{\tau} & =G\left(\underline{\underline{\sigma^{\prime}}}\right) \dot{\underline{\gamma}}^{e}
\end{aligned}\right.
$$

where $E^{*}$ and $G$ are the constrained and shear modules.

Modeling the elastoplastic behaviour The yield function of the constitutive model presented here may be considered as a generalization of the Coulomb Friction law, in which some aspects such as the dependency on the state of compactness and the evolving friction mobilization, similar to those used in ECP family models (Aubry et al., 1982; Hujeux, 1985; Aubry et al., 1990), are included. It represents a shearing on a plane and incorporates dilatancy-contractance in the direction normal to that plane. Therefore, the model is a derivation of the 3D model with some improvements. A vectorial formulation of the constitutive model permits plastic coupling effects between shearing and the plastic volumetric strain to be taken into account. The model is written in terms of effective stresses. Fundamental aspects of soil behaviour such as evolving plasticity, dilatancy and contractance, softening and hardening and cyclic hysteretic behaviour are included.

Following the incremental elastoplasticity theory, the rate of total strain is decomposed into reversible and irreversible parts:

$$
\left\{\begin{array}{l}
\dot{\varepsilon}=\dot{\varepsilon}^{e}+\dot{\varepsilon}^{p} \\
\dot{\gamma}=\dot{\gamma}^{e}+\dot{\gamma}^{p}
\end{array}\right.
$$

where $\left(\varepsilon^{p}, \gamma^{p}\right)$ are normal and shear plastic strains on the surface normal to the wave propagation direction. The dot designates derivation with respect to time. Hence, combining (1) and (2) gives:

$$
\left\{\begin{array}{c}
\dot{\sigma}^{\prime}=E^{*}\left(\dot{\varepsilon}-\dot{\varepsilon}^{p}\right) \\
\underline{\dot{\tau}}=G\left(\underline{\dot{\gamma}}-\underline{\dot{\gamma}}^{p}\right)
\end{array}\right.
$$

Both monotonous and cyclic loadings can be defined by a yield surface as follows:

$$
f\left(\sigma^{\prime}, \underline{\tau}, \varepsilon^{p}, r\right)=\left\|\underline{\tau}^{c}\right\|+\sigma^{\prime} \cdot F \cdot\left|r^{c}\right|
$$


where $\|\underline{a}\|=(\underline{a} \cdot \underline{a})^{1 / 2}$ and $|a|$ designates the absolute value of $a$. $r^{c}=r-r_{o}$ and $\underline{\tau}^{c}=\underline{\tau}-\frac{\sigma^{\prime} F}{\sigma_{o}^{\prime} F_{o}} \underline{\tau}_{o}$. The index $o$ corresponds to the value of the variable at the latest loading reversal during the cyclic loading. The above formulation is advantageous as it can be applied to cyclic as well as monotonous (primary) loading where $\underline{\tau}_{o}$ and $r_{o}$ will be zero.

Isotropic hardening is taken into account by means of $F$ and $r$. The function $F$ permits to control the isotropic hardening associated with the plastic volumetric strain, whereas $r$ accounts for the isotropic hardening generated by plastic shearing. It represents progressive friction mobilization in the soil and reaches its maximum value at perfect plasticity. $F$ can be expressed as follows:

$$
F=1-b \ln \left(\frac{\sigma^{\prime}}{\sigma_{c}}\right)
$$

with $\sigma_{c}$, the critical effective stress:

$$
\sigma_{c}=\sigma_{c o} \exp \left(-\beta \varepsilon^{p}\right)
$$

The parameter $b$ controls the form of the yield surface and varies from 0 to 1, passing from a Coulomb type surface to a Cam-Clay one (figure 1). A kinematical hardening is introduced during the loadingunloading cycles through the internal variable $r$. This latter is related to the plastic shear strain as follows:

$$
r\left(\gamma^{p}\right)=r_{o}+\left(r_{m}-r_{o}\right)\left(\frac{\left|\gamma^{p}-\gamma_{o}^{p}\right|}{\frac{\left|r_{m}-r_{o}\right|}{E_{p}}+\left|\gamma^{p}-\gamma_{o}^{p}\right|}\right)^{n_{r}}
$$

with:

$$
r_{m}= \begin{cases}\tan \phi^{\prime} & \text { load } / \text { reload } \\ -\tan \phi^{\prime} & \text { unload }\end{cases}
$$

where $\phi^{\prime}$ is the friction angle at the critical state; $\gamma^{p}$ is the plastic shear strain accumulated during the shearing $\left(\gamma^{p}=\int_{0}^{t}\left\|\dot{\hat{\gamma}}^{p}\right\| d t\right) ; \gamma_{o}^{p}$ is the plastic shear strain accumulated at the very beginning of the loading until the last loading/reloading $\left(\gamma_{o}^{p}=\int_{0}^{t_{0}}\left\|\dot{\gamma}^{p}\right\| d t\right)$ and $n_{r}$ is a numerical parameter which guarantees a smooth evolution towards perfect plasticity (figure 2). $E_{p}$ is the plastic modulus which governs the evolution of shear strains.

When the plastic strains grow dramatically in the soil, the function $r$ reaches its maximal value $r_{m}$ asymptotically:

$$
\lim _{\gamma^{p} \rightarrow+\infty} r=r_{m} \text { or } \lim _{\gamma^{p} \rightarrow+\infty}\|\underline{\tau}\|=-\sigma^{\prime} F\left|r_{m}\right|
$$




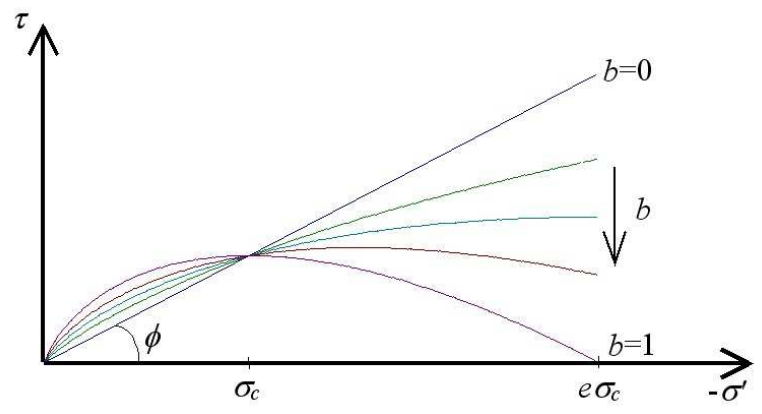

Figure 1. Influence of parameter b on the yield surface shape

Plastic volumetric strains associated with plastic shear strains are evaluated using a Roscoe-type dilatancy rule (Schofield and Wroth, 1968):

$$
\left\{\begin{array}{l}
\dot{\varepsilon}^{p}=\dot{\lambda}^{p} \Psi_{v} \\
\dot{\hat{\gamma}}^{p}=\dot{\lambda}^{p} \underline{\Psi}_{d}
\end{array}\right.
$$

where $\dot{\lambda}^{p}$ is the plastic multiplier.

$$
\left\{\begin{array}{l}
\Psi_{v}=-\alpha_{\psi} \zeta(r)\left(\tan \psi+\frac{\left\|\underline{\tau}^{c}\right\|}{\sigma^{\prime}}\right) \\
\underline{\Psi}_{d}=\partial_{\underline{\tau}} f=\frac{\underline{\tau}^{c}}{\left\|\underline{\tau}^{c}\right\|}
\end{array}\right.
$$

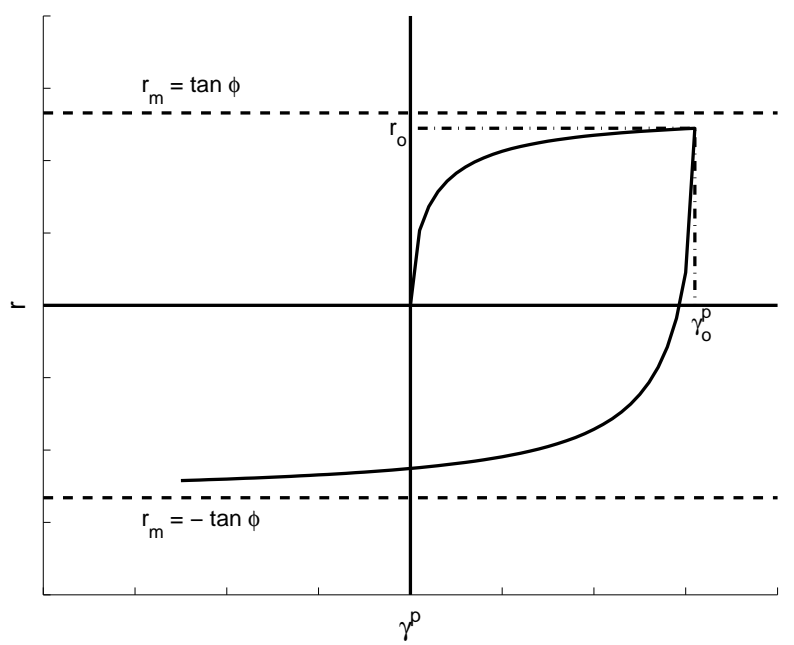

Figure 2. Loading/unloading cycle 
$\psi$ is the characteristic angle, defining the limit between dilatancy and contractance of the material (figure 3$). \zeta(r)$ has been introduced to control pore-pressure or volumetric strain evolution. It is zero for very low strains, equal to unity for large strains and varies from 0 to 1 for the intermediate range of strains. The parameter $\alpha_{\psi}$ is a constant parameter which enhances the model's performances. Set to zero, the plastic contractance or dilatance can be inhibited. In all our computations the unit value has been adopted.

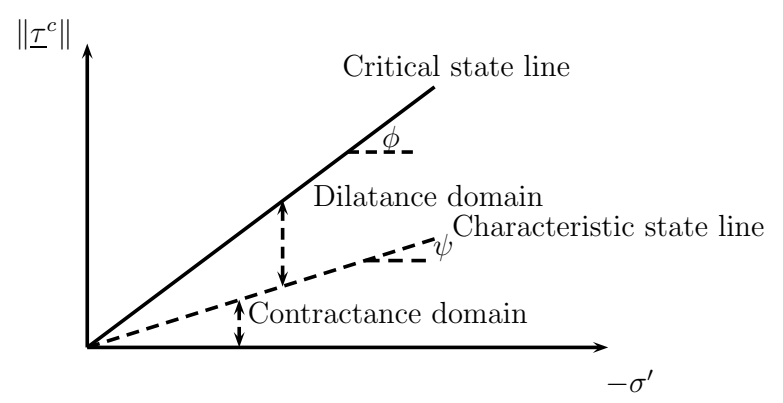

Figure 3. Critical State and Chacteristic State Lines

$\zeta(r)=\left\{\begin{array}{llll}0 & \text { if } & \left|r-r_{o}\right|<r_{h y s} & \text { elastic domain } \\ \left(\frac{\left|r-r_{o}\right|-r_{h y s}}{r_{m o b}-r_{h y s}}\right)^{2} & \text { if } & r_{h y s}<\left|r-r_{o}\right|<r_{m o b} & \text { hysteretic domain } \\ 1 & \text { if } & r_{m o b}<\left|r-r_{o}\right|<1 & \text { mobilized domain }\end{array}\right.$

with:

$$
\begin{aligned}
& r_{h y s}=\left|r_{m}-r_{o}\right|\left(\frac{\gamma^{h y s}}{\frac{\left|r_{m}-r_{o}\right|}{E_{p}}+\gamma^{h y s}}\right)^{n_{r}} \\
& r_{m o b}=\left|r_{m}-r_{o}\right|\left(\frac{\gamma^{m o b}}{\frac{\left|r_{m}-r_{o}\right|}{E_{p}}+\gamma^{m o b}}\right)^{n_{r}}
\end{aligned}
$$

1

Plastic coupling Because of the plasticity mechanism, there are two types of coupling between different components of the seismic motion. 
The first concerns the two in plane components as the yield function depends of the amplitude of the shear stress, implying the interdependence of the plastic strain vectors and thus the shear stress and strain evolution in both directions. The second coupling links the normal and the in plane movements. Due to equations 9 and 10, the induced increment of normal plastic strain is proportional to the amplitude of the increment of the shear strain : $\dot{\varepsilon}^{p}=\Psi_{v}\left\|\dot{\gamma}^{p}\right\|$. Moreover, the increments of the shear and normal stresses depend on the increment of the plastic shear strain vector in the plane (equation 3). This explains importance of taking into account all the components of shear strain. To these direct coupling effects, we can add the role of normal strain (normal stress) on the evolution of the yield function which controls the amplitude of the shear strains.

In practice, the computations of the seismic soil motion are carried out with each component of the input motion separately (i.e. each horizontal or vertical component). The coupling due to plasticity prohibits such individualized computations and enforces the need to perform computations with three components of the input motion simultaneously.

\section{Elastoplastic constitutive model parameters}

As already mentioned, the parameters of the model concern both the elastic and plastic behaviour of the soil (table I). The model parameters are classified according to their estimation method. From this point of view, the parameters used in the elastoplastic model are separated into two categories: those that can be directly measured either in-situ or in the laboratory and those which cannot be directly measured.

\subsection{Determination of Directly measurable Parameters}

\subsubsection{Elastic parameters}

The isotropic elasticity assumption imposes the following relation between the shear and compression wave velocities and the Poisson's ratio $\nu:\left(v_{p} / v_{s}\right)^{2}=2(1-\nu) /(1-2 \nu)$. It shows that only two of the above three parameters have to be determined. When shear wave velocity measurement is not available, it can be estimated by: $v_{s}^{2}=G_{\max } / \rho$, where $G_{\max }$ is the maximum shear modulus measured at small strains and $\rho$ is soil density.

3.1.1.1. Clays Laboratory test data suggest that the maximum shear modulus $G_{\max }$ is a function of the void ratio $e$, the over-consolidation 
Table I. Parameter classification according to their estimation method

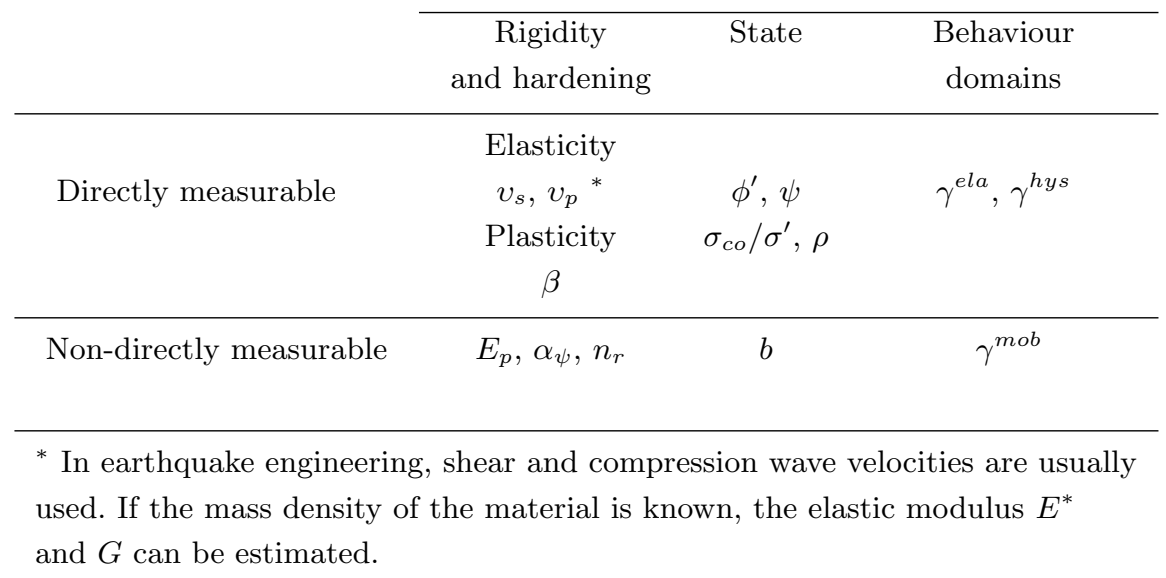

ratio $O C R$ and the mean effective stress $\sigma^{\prime}$ (Hardin, 1978; Vucetic and Dobry, 1991; Kramer, 1996; Kallioglou et al., 1999). Empirical relations can be used to determine this parameter according to the soil type. Figure 4 shows a comparison between the shear modulus obtained with different relations (Hardin, 1978; Kokusho et al., 1982; Anastasiadis and Pitilakis, 1996; Kallioglou et al., 1999; Santos, 1999) for a normally consolidated clay at $\sigma^{\prime}=100 k P a$ as a function of voids ratio $e$. For the overconsolidated clays, an additional multiplying parameter of the type $O C R^{k}$ can be used. $k$ is a factor depending on the plasticity index $I_{p}$, such that for $I_{p}$ between $0-100 \% k$ varies from 0 to 0.5 (Hardin, 1978).

3.1.1.2. Sands As in clays, the maximum shear modulus $G_{\max }$ of sands can be expressed as a function of the void ratio $e$ and the mean effective stress $\sigma^{\prime}$. After Kohata et al. (1997), the variation of maximum modulus as a function of the confinement pressure obtained for different tested sands and gravels is very close. Thus, we propose to use the following relationship (Iwasaki et al., 1978) for the sand:

$$
G_{\max }=900 \frac{(2.17-e)^{2}}{1+e} \sigma^{0.4} p_{a}^{0.6}
$$

\subsubsection{Plastic compressibility modulus $\beta$}

The plastic compressibility modulus $\beta$ can be expressed in terms of the $\lambda$ parameter of the Cam-Clay model using the following relationship:

$$
\beta \simeq \frac{1+e}{\lambda}
$$


$\lambda$ represents the slope of the virgin consolidation line of an isotropic compression test expressed in the $\left(e-\ln \sigma^{\prime}\right)$ plane. This parameter is related to the compression index $C_{c}$ through: $C_{c}=2.3 \lambda$.

3.1.2.1. $C_{c}$ and $e$ for Clays For a normally consolidated clay, the following relation exists between the voids ratio $e$ and the vertical effective stress $\sigma^{\prime}: e=e_{0}-C_{c} \log \left(\sigma^{\prime}\right)$. Different authors propose a correlation between $I_{p}$ and $C_{c}$ (Biarez and Hicher, 1994; Bardet, 1997). In this paper, we use the correlation given by Biarez and Favre (1972), $C_{c}=0.009\left(w_{L}-13\right)$ where $w_{L}$ is the liquidity limit. The strategy for the determination of $e$ knowing the effective vertical stress is shown in

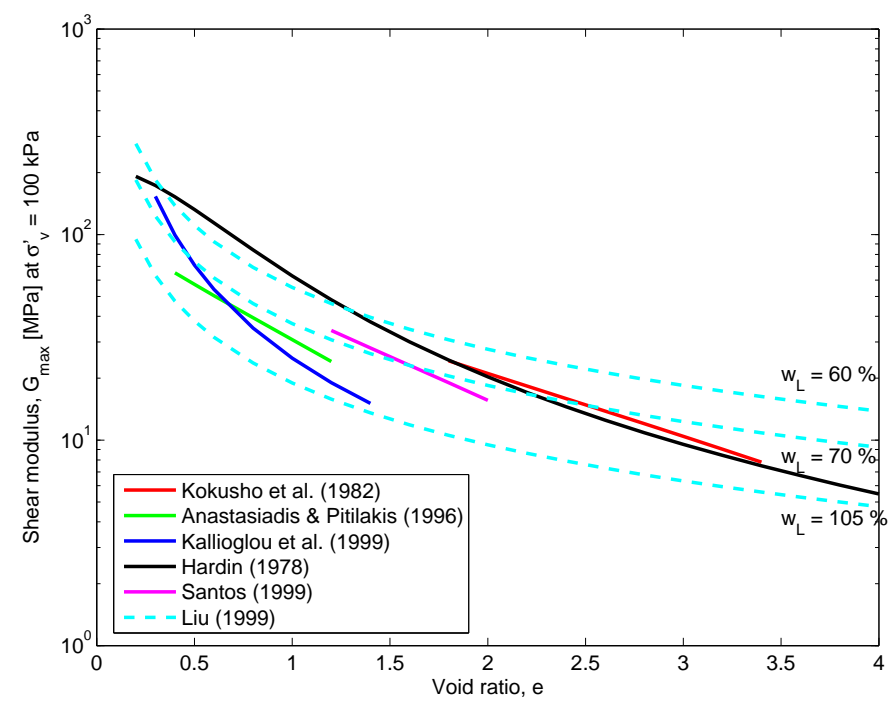

Figure 4. Comparison of different relationships given for the maximum shear modulus.

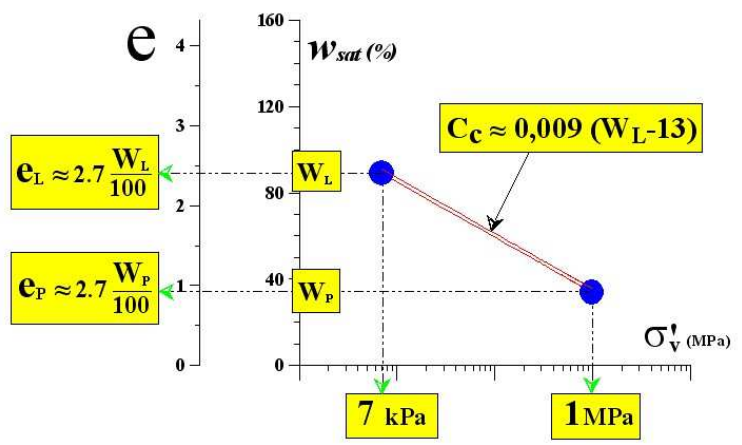

Figure 5. The slope and the position of the oedometric compressibility curve for normally consolidated clays. (Biarez and Favre, 1972). 
figure 5, where, as it can be seen, $e$ is equal to $G_{S} w_{L} / 100$ for $\sigma^{\prime}=7 \mathrm{kPa}$ and $G_{S} w_{p} / 100$ for $\sigma^{\prime}=1 \mathrm{MPa}$, where $G_{S}$ is the soil specific gravity.

3.1.2.2. $C_{c}$ for Sands Saim (1997) proposes a correlation between $C_{c}$ and the minimum and maximum void ratios $e_{\min }$ and $e_{\max }$ for sands, where the relative density $D_{r}$ is equal to 0 for $\sigma_{v}^{\prime}=100 \mathrm{kPa}$ and 1 for $\sigma_{v}^{\prime}=5 \mathrm{MPa}$ at critical state. When the void ratio measurement is not available, it can be estimated by some correlations relating the $e_{\min }$ and $e_{\max }$ of sandy materials with respect to their grain size distribution (Biarez and Hicher, 1994).

In another approach, Hicher and Rahma (1994) propose a more general relation (eq. 15) to obtain the $\beta$ value, by using a large sandy soil database. Thus parameter $\beta$ is given by the following relationship:

$$
\beta=2.3(1+e) \frac{\beta_{\text {norm }}}{I_{e}}
$$

$I_{e}$ is the consistance index $\left(I_{e}=e_{\max }-e_{\min }\right)$ and $\beta_{\text {norm }}$ is given as:

$$
\begin{aligned}
\beta_{\text {norm }} & =\log P^{\prime} c_{\max }-\log P^{\prime} c_{\text {min }} \\
\log P^{\prime} c_{\text {max }} & =-4 \log U_{c}-7.5 \cdot e_{\min }+4.75 \cdot I_{e}+7.1 \pm 0.3 \\
\log P^{\prime} c_{\text {min }} & =-12 \log C_{z}-4.7 \cdot e_{\max }+9.71 \cdot I_{e}+2.2 \pm 0.5
\end{aligned}
$$

$U_{c}$ is the uniformity coefficient $\left(d_{60} / d_{10}\right)$, where $d_{i}$ designates the diameter of the grains representing $i \%, C_{z}$ is the coefficient of curvature $\left(d_{30}^{2} / d_{60} \cdot d_{10}\right) . P^{\prime} c_{\max }$ and $P^{\prime} c_{\min }$ are the mean effective stress for $e_{\min }$ and $e_{\max }$ respectively.

\subsubsection{Determination of $\phi^{\prime}$ and $\psi$}

For clays, Biarez and Hicher (1994) give a correlation between the friction angle $\phi^{\prime}$ and the Plasticity Index $I_{p}$. In this correlation $\phi^{\prime}$ decreases from $32^{\circ}$ to $20^{\circ}$ when $I_{p}$ varies from $5 \%$ to $65 \%$ following this relationship:

$$
\phi^{\prime}=44.5\left(\frac{1}{I_{p}}\right)^{0.17}
$$

Favre (1980) gives the following relationship for the friction angle of sands:

$$
\phi^{\prime}=31.5^{\circ}+\phi_{D}+\phi_{F}+\phi_{U_{c}}
$$

where $\phi_{D}, \phi_{F}$ and $\phi_{U_{c}}$ are used to account for granulometric features such as grain size, angularity and grain size distribution respectively. The sum of these coefficient values varies in the range of $\pm 2.5^{\circ}$. 
As already mentioned, $\psi$ represents the limit between contracting and dilating behaviours in sands, which is known as the "phase transformation state" or "quasi-steady state" (Ishihara et al., 1975; Ishihara, 1993). The value of this parameter may be equal or less than $\phi^{\prime}$. In the case of clays, $\psi=\phi^{\prime}$ can be chosen.

\subsubsection{Initial state parameters}

In the CyberQuake model, the initial state of the soil is given by the compaction ratio $\sigma_{c o} / \sigma^{\prime}$. This parameter represents the position of the critical state pressure $\sigma_{c o}$ with respect to the initial pressure $\sigma^{\prime}$. If we neglect the elastic volumetric strain, $\sigma_{c o}$ can be defined as the pressure in the critical state line corresponding to the same void ratio as the initial pressure $\left(\sigma^{\prime}\right)$. The $\sigma_{c o} / \sigma^{\prime}$ ratio is a function of the initial density of the soil and the position of the initial void ratio with respect to the critical state line in the $\left(e-\ln \sigma^{\prime}\right)$ plane.

Thus, in the case of clays, this ratio remains constant for a given $O C R$ at different initial pressures. Nevertheless, for sands, $\sigma_{c o}$ remains constant for a given $D_{r}$ at different initial pressures. This parameter can be estimated by using different factors proposed to characterize both the response of clays and sands.

For clays, the compaction ratio can be estimated by the following relationship:

$$
\frac{\sigma_{c o}}{\sigma^{\prime}}=\frac{S u}{\sigma^{\prime} \tan \phi^{\prime}}
$$

where $S_{u}$ is the undrained shear strength $\left(S_{u}=\left(\sigma_{1}^{\prime}-\sigma_{3}^{\prime}\right) / 2=\tau_{\max }\right)$. For sands, it can be obtained using the following expression:

$$
\frac{\sigma_{c o}}{\sigma^{\prime}}=\exp \left(-2.3 \frac{\psi_{B J}}{C_{c}}\right)
$$

$\psi_{B J}$ is the "state index" parameter given by Been and Jefferies (1985).

\subsection{Determination of nON-Directly measurable PARAMEters}

As the Cam-Clay yield surface represents the behaviour of clays better, while the Mohr-Coulomb is more adapted for sands, the value of $b$ is determined with respect to this consideration (i.e. $b \simeq 0.1-0.2$ for sands and $b=1.0$ for clays). The parameter $n_{r}$ has been chosen equal to 0.5 for all cases. 


\subsubsection{Behaviour domains}

The parameters $\gamma^{\text {ela }}, \gamma^{\text {hys }}$ and $\gamma^{\text {mob }}$, are very important in liquefaction studies. They enable the decomposition of soil behaviour into pseudoelastic, hysteretic and mobilized domains. These parameters control the degradation hysteresis and the water pore-pressure change in undrained conditions or the volumetric change in drained conditions. $\gamma^{e l a}$, which takes very small values, defines the elastic domain in which no plastic shear strain occurs. $\gamma^{\text {hys }}$ defines the plastic shear strain beyond which volumetric effects appear under shearing. This latter effect evolves according to relation 11 .

To estimate $\gamma^{\text {hys }}$ and $\gamma^{\text {mob }}$, a strain controlled cyclic shear (SCCS) test can be simulated in order to find the volumetric threshold shear strain $\gamma_{t v}$ (Dobry et al., 1982; Vucetic, 1994). In order to study the influence of these parameters in the model response, three undrained SCCS tests are simulated (figure 6) and only the value of $\gamma^{\text {hys }}$ is changed. According to this figure, the variation of $\gamma^{\text {hys }}$ value modifies the $\gamma_{t v}$ obtained.

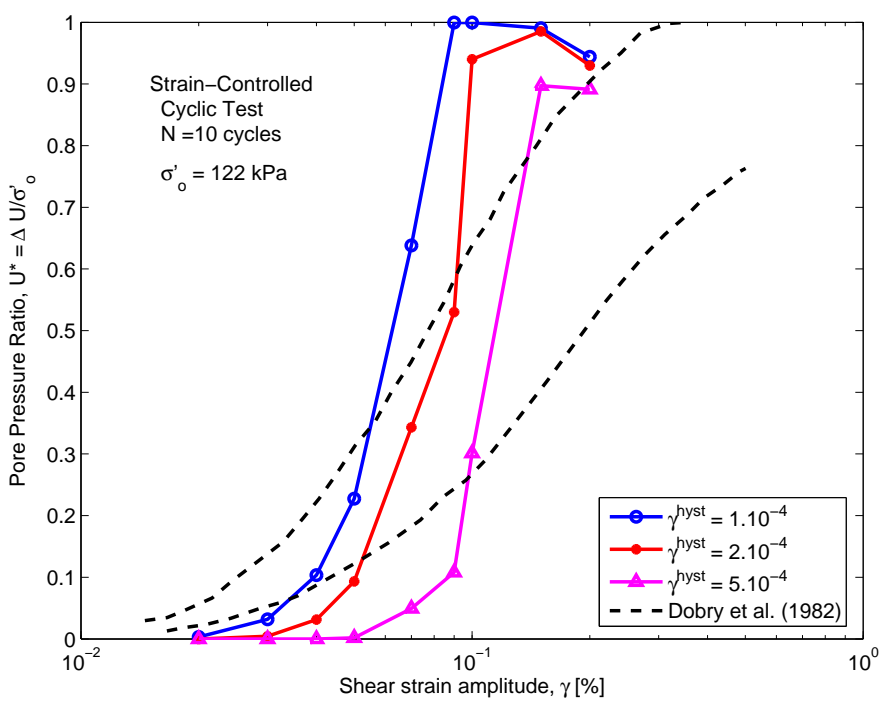

Figure 6. Effect of variation de $\gamma^{\text {hys }}$ in the model response of a strain controlled cyclic shear (SCCS) test. Comparison with Dobry et al. (1982) curves.

\subsubsection{Plasticity modulus of rigidity $E_{p}$}

The parameter $E_{p}$ governs the evolution of the yield surface toward total plastic mobilization. It will be determined in order to match the $G-\gamma$ and $D-\gamma$ curves for each type of soil. Several authors have summarized such curves (Kokusho, 1980; Seed et al., 1986; Sun et al., 1988; Vucetic and Dobry, 1991; Ishibashi and Zhang, 1993; Darendeli, 
2001), according to the material type. As it is a conceptual example in this part of the work, the compiled curves of Vucetic and Dobry (1991) and those of Kokusho (1980) have been used as "measured" curves for clays and sands respectively.

In order to study the influence of several features of soil behaviour on the $E_{p}$ parameter, cyclic shear tests at different initial states have been simulated for both clays and sands. Using a statistical analysis of used data (Figure 7), we can propose the following relationship to estimate the $E_{p}$ value for clays and sands (equation 21 and 22) respectively:

$$
\begin{aligned}
& E_{p}=C_{1} \exp \left(\chi_{c l} \frac{G_{\max }}{\sigma^{\prime} \cdot O C R}\right) \\
& E_{p}=C_{2} \exp \left(\chi_{\operatorname{san}} \frac{G_{\max }}{\sigma_{c o}}\right)
\end{aligned}
$$

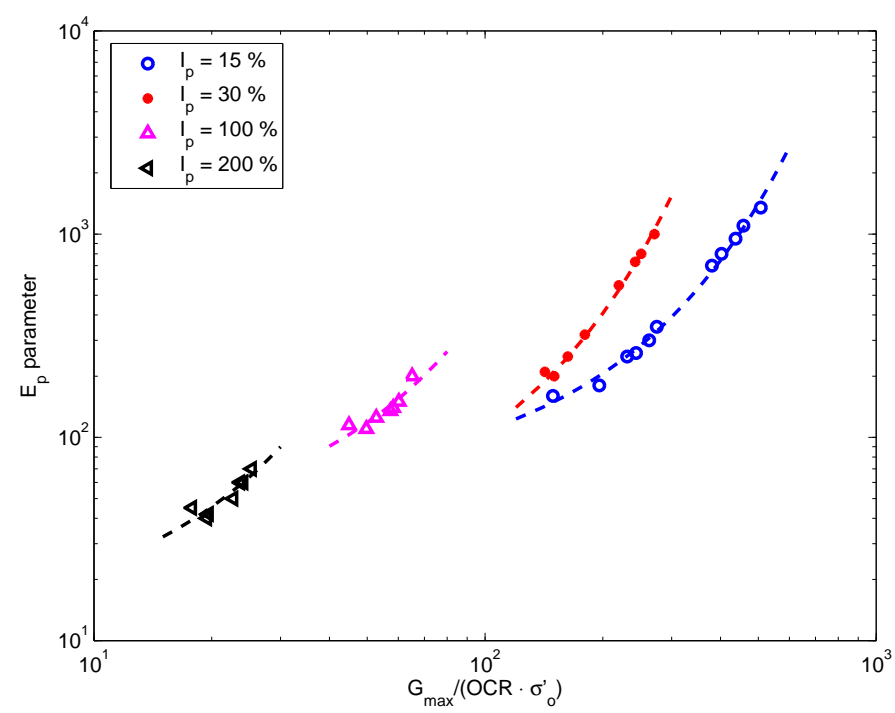

Figure 7. Variation of $E_{p}$ parameter as a function of $G_{\max }, O C R$ and $\sigma^{\prime}$ for different $I_{p}$ values (Case of clays).

where $C_{1}, \chi_{c l}$ and $C_{2}, \chi_{\text {san }}$ are factors depending on the $I_{p}$ and $D_{r}$ respectively (Table II).

Finally, the whole methodology for the determination of elastoplastic model parameters for clays and sands is summarized in figures 8 and 9 . As can be noted in these figures, for a given soil profile, the knowledge of one state parameter (i.e. $O C R$ for clays and $D_{r}$ for sands) and one parameter independent of the soil arrangement (i.e. Liquidity Limit of clays $w_{L}$ and $e_{\min }$ and $e_{\max }$ for sands) is enough to obtain a set of model parameters, which can probably be refined if complementary data are available. 


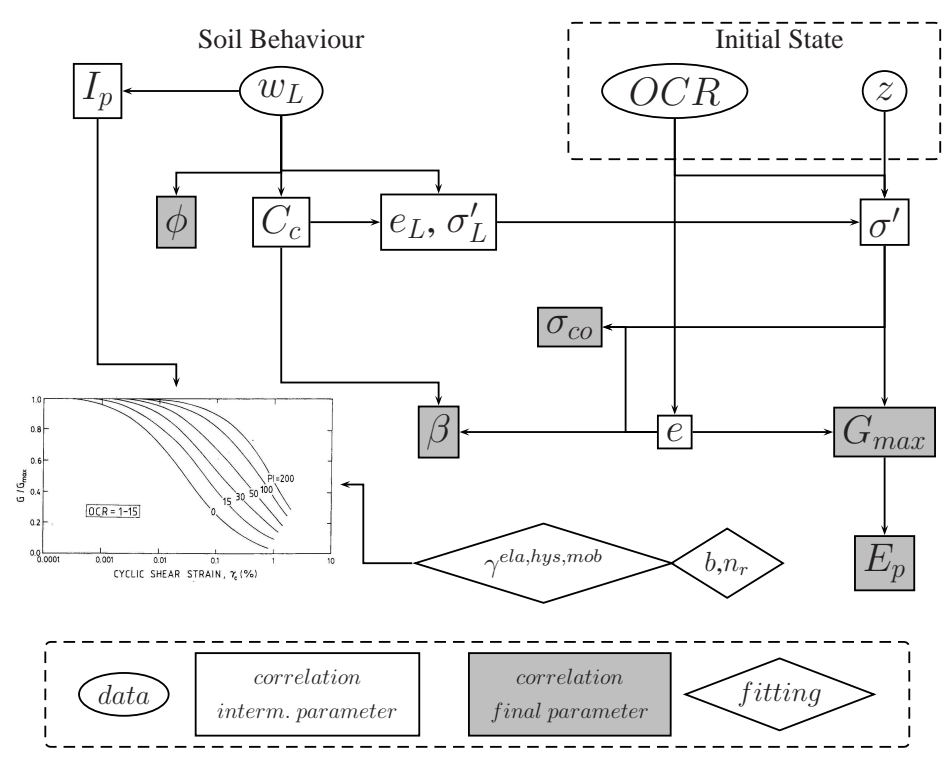

Figure 8. Methodology for elastoplastic model parameter identification of clays

\section{Model response for laboratory tests}

In order to validate the proposed methodology and the coherence of the obtained set of parameters, we have studied clay and sand behaviours at different initial states (i.e. different values of $\sigma^{\prime}$ and $O C R$ or $D_{r}$ ). The constitutive model parameters are then obtained by simulating the monotonic and cyclic tests.

\subsection{TESTS FOR CLAYS}

The model parameters were determined as described above and the undrained strain-controlled monotonous and cyclic direct simple shear

Table II. Values of coefficients of relations 21 and 22 to estimate the values of $E_{p}$ parameter.

\begin{tabular}{cccccc}
\hline \multicolumn{3}{c}{ Clay } & \multicolumn{3}{c}{ Sand } \\
\hline$I_{p}(\%)$ & $C_{1}$ & $\chi_{c l}$ & $D_{r}(\%)$ & $C_{2}$ & $\chi_{\text {san }}$ \\
\hline 15 & 57.1 & $6.41410^{-3}$ & 10 & 2256 & $-1.710^{-3}$ \\
30 & 31.0 & $1.29510^{-2}$ & 20 & 1895 & $-2.110^{-3}$ \\
100 & 31.0 & $2.68110^{-2}$ & 50 & 2613 & $-5.810^{-3}$ \\
200 & 11.7 & $6.80010^{-2}$ & & & \\
\hline
\end{tabular}


tests were simulated. These tests were made for an $I_{p}=15 \%$ clay at three initial states and different $O C R$ values (i.e. 1.0, 2.0 et 3.0). The confining pressures $\left(\sigma^{\prime}\right)$ used are 64,70 and $189 \mathrm{kPa}$. Figure 10 shows the model prediction for the variation of $G / G_{\max }$ and the variation of damping ratio $(D)$ with the cyclic shear strain $\gamma$ for the undrained strain-controlled cyclic direct simple shear test. These curves are compared with the modulus reduction curve and the damping ratio for $I_{p}=15 \%$ clay given by Vucetic and Dobry (1991). The shear modulus $(G)$ obtained by the elastoplastic model is in good accordance with the given curve, though the model overestimates the damping for high shear strains.

In order to define the different states of the clay (i.e. different $O C R$ values), undrained monotonic simple shear tests are simulated. Figure 11 shows the results of such tests obtained in the $\tau-\gamma$ plane. In order to verify the validity of the proposed model parameters, we have plotted the variation of the $\left(\tau / \sigma^{\prime}\right)$ ratio with respect to the shear strain $(\gamma)$ in figure 12. It shows that the soil behaviour is always contracting when $O C R=1$ and dilating for $O C R>1$, where the material exceeds the critical state line before reaching perfect plasticity. Therefore, for overconsolidated material, resistance degradation is also modeled. In addition, the comparison of the $S_{u}$ values obtained in the numerical simulation are in perfect coherence with the empirical correlations, as

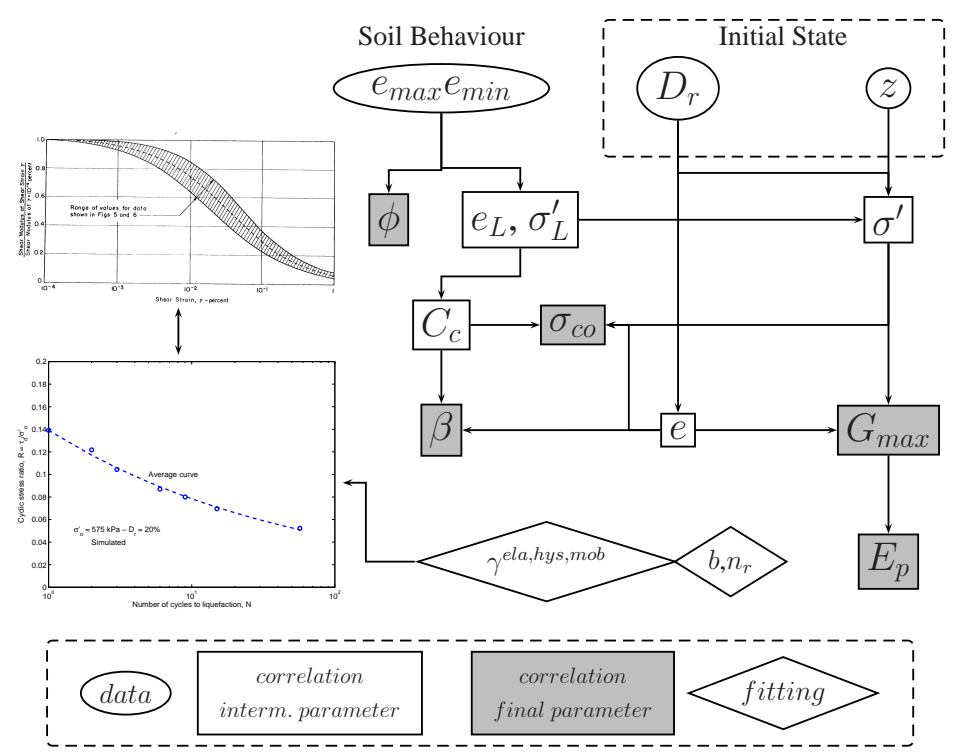

Figure 9. Methodology for elastoplastic model parameter identification of sands 


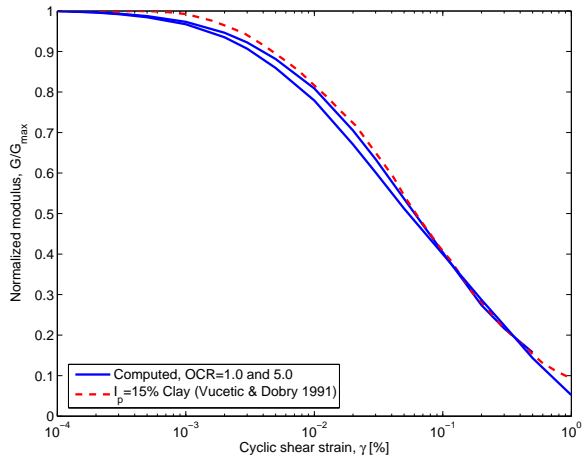

a.

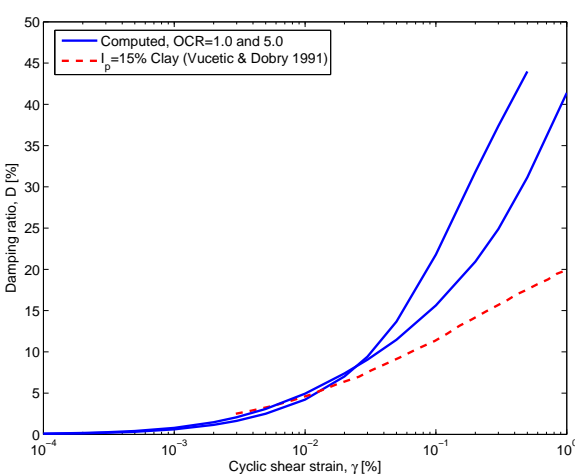

b.

Figure 10. Comparison between simulated and Vucetic and Dobry (1991) reference curves for $I_{p}=15 \%$ clay model : a) $G / G_{\max }-\gamma$ and b) $D-\gamma$.

for example, that given by Jamiolkowski et al. (1985):

$$
\frac{S_{u}}{\sigma^{\prime}}=(0.23 \pm 0.04) O C R^{0.8}
$$

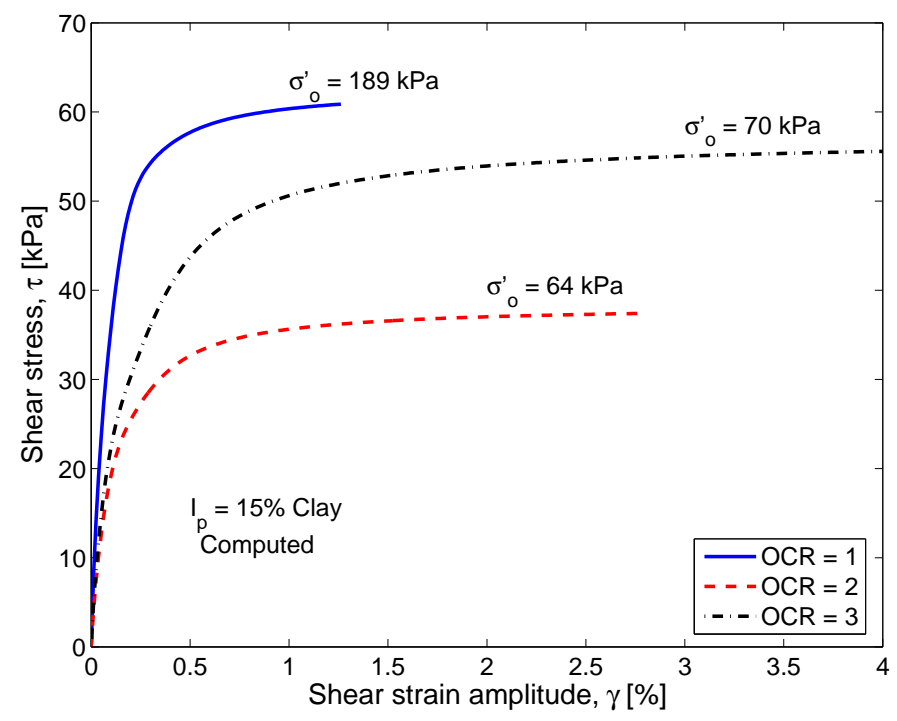

Figure 11. Simulated variation of shear stress $\tau$ with shear strain $\gamma$ for 3 undrained simple monotonic shear tests. $I_{p}=15 \%$ clay model.

where $\sigma_{m}^{\prime}$ is the initial vertical effective stress. In the simulation, $S_{u} / \sigma^{\prime}$ values of $0.34,0.60$ and 0.80 are obtained for $O C R$ of $1.0,2.0$ and 3.0 respectively. 


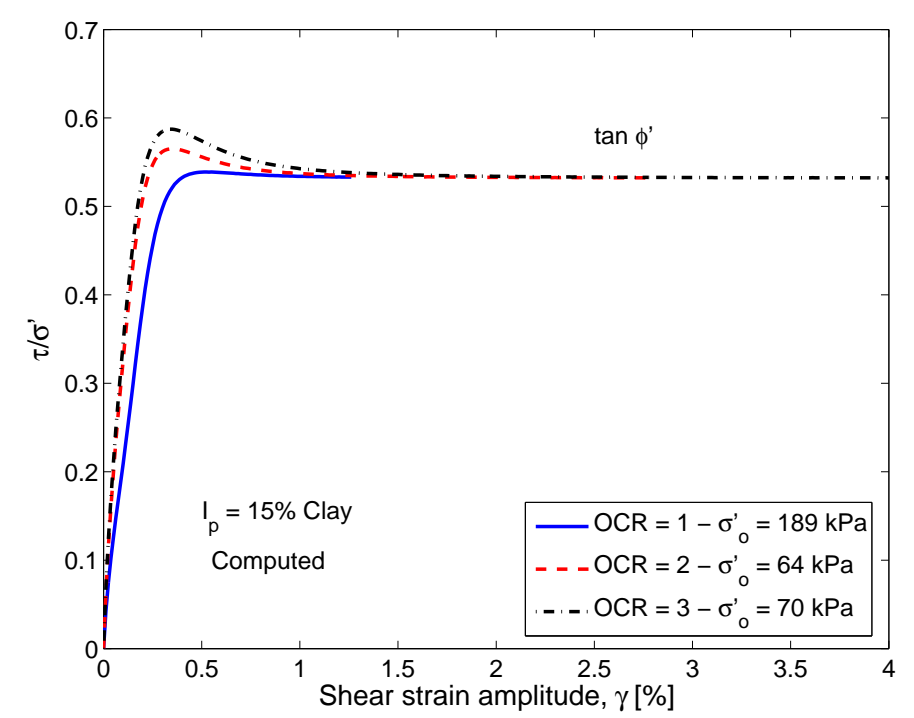

Figure 12. Simulated variation of $\tau / \sigma^{\prime}$ with shear strain $\gamma$ for 3 undrained simple monotonic shear tests. $I_{p}=15 \%$ clay model.

\subsection{TESTS FOR SANDS}

In this section, a unique type of sand with different $D_{r}$ at several initial confining pressures is studied. The main characteristics of the sand used are as follows: $C_{u}=1,3, C_{z}=1.0, e_{\min }=0.58$ and $e_{\max }=0.98$. Once the parameters are estimated, undrained cyclic strain-controlled shear tests are simulated to verify the coherence of the parameters.

Figures 13 and 14 show the response obtained by the model with $D_{r}=20 \%$ for the monotonic test in the $\tau-\gamma$ and $\tau-\sigma^{\prime}$ planes.

Figure 15 shows the simulated response of a drained cyclic straincontrolled shear test for the sand at $D_{r}=40 \%$ and two $\sigma^{\prime}$ (20 and $300 \mathrm{kPa}$ ). The obtained $G / G_{\max }-\gamma$ and $D-\gamma$ curves are compared to the reference curves given by Kokusho (1980) for sands at the same initial pressure. As can be noticed, the $G / G_{\max }-\gamma$ curves match relatively well for both $\sigma^{\prime}$ values. Nevertheless, for strains larger than $0.01 \%$, the damping ratio $D$ is over-estimated.

In the case of sands, the cyclic tests are related principally to the study of liquefaction problems. In order to characterize the liquefaction resistance of a sand with $D_{r}=20 \%$, undrained cyclic shear tests were simulated. Both approaches, stress controlled and strain controlled, were used. The first one gives a curve of cyclic stress ratio $\left(R=\tau_{d} / \sigma^{\prime}\right)$ as a function of the number of loading cycles to produce liquefaction $(N)$ (Figure 16). The second approach, proposed by Dobry et al. (1982), produces a curve of pore pressure ratio $\left(r_{u}=\Delta U / \sigma^{\prime}\right)$ after 10 cycles as 


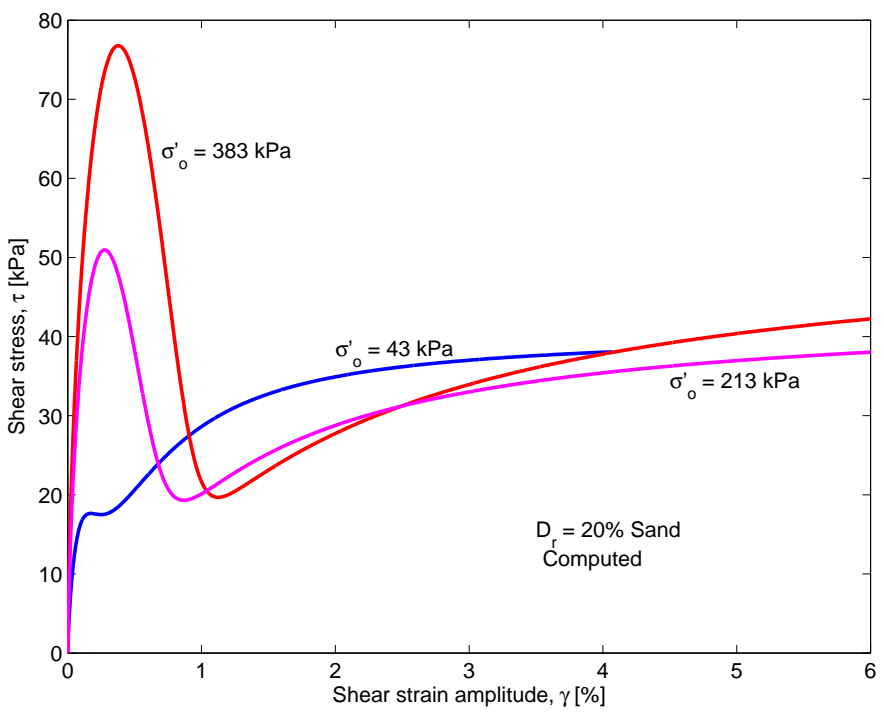

Figure 13. Simulated variation of shear stress $\tau$ with shear strain $\gamma$ for 3 undrained simple monotonic shear tests. $D_{r}=20 \%$ sand model.

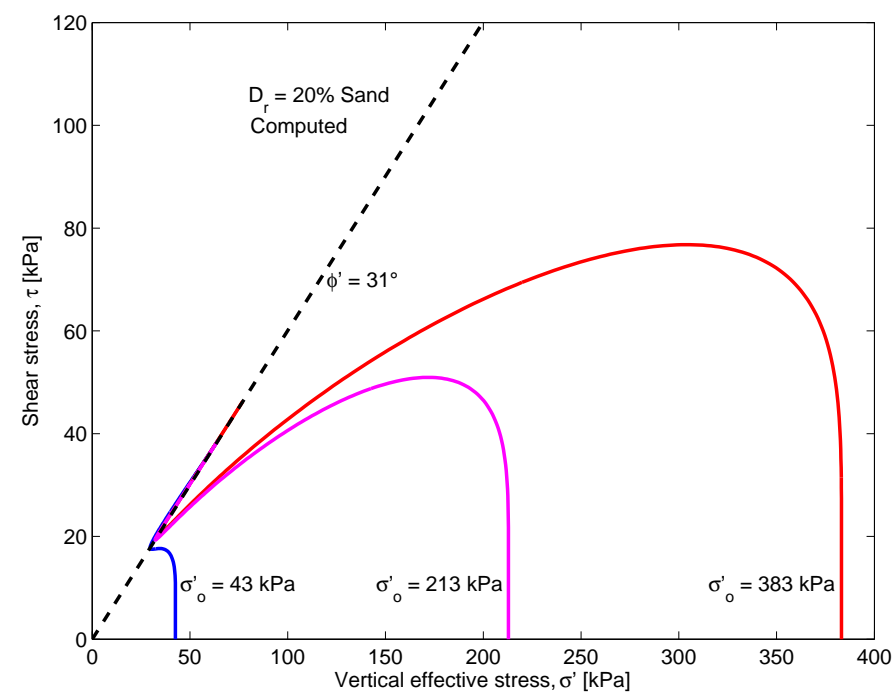

Figure 14. Simulated variation of shear stress $\tau$ with normal stress $\sigma^{\prime}$ for 3 undrained simple monotonic shear tests. $D_{r}=20 \%$ sand model.

a function of cyclic strain (Figure 17). According to these figures, the model responses for both loading paths are coherent for the same initial conditions (i.e. $D_{r}$ and $\sigma^{\prime}$ ) and both of them can be used to validate the model. 


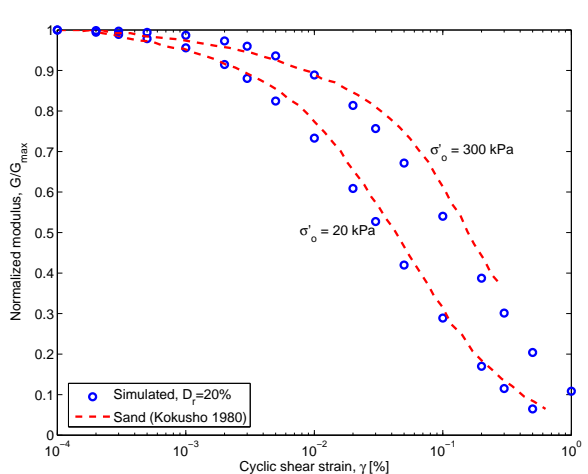

a.

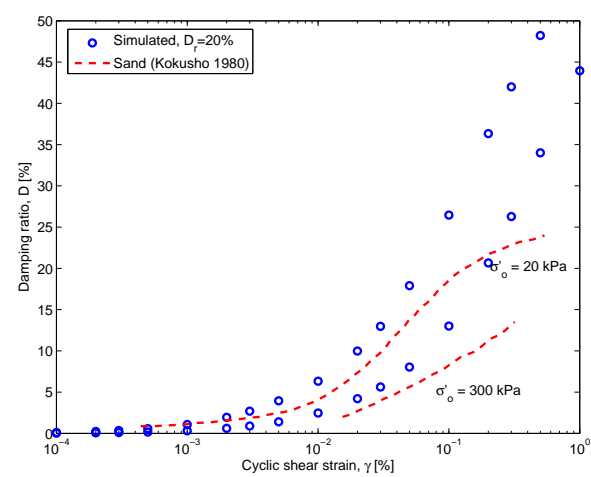

b.

Figure 15. Comparison between simulated and Kokusho (1980) reference curves for sand $D_{r}=20 \%$ model : a) $G / G_{\max }-\gamma$ and b) $D-\gamma$.

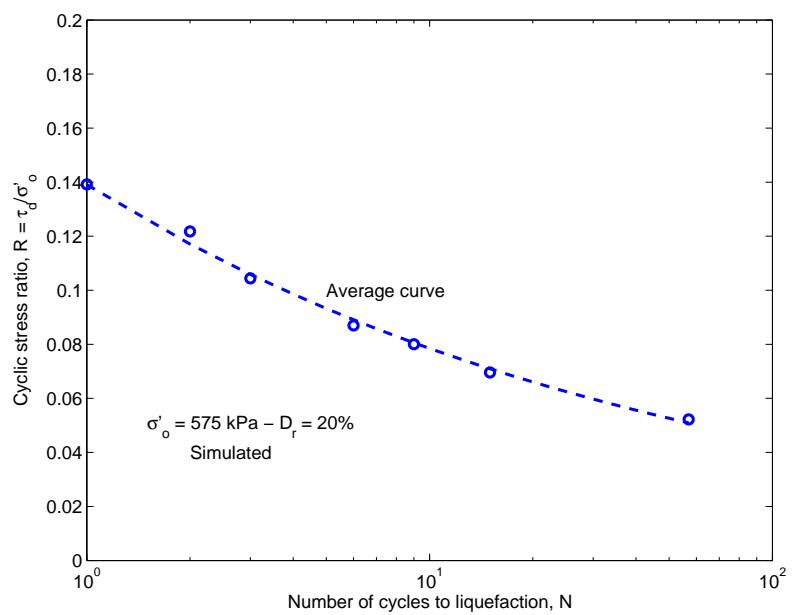

Figure 16. Simulated $D_{r}=20 \%$ sand model liquefaction curves, stress controlled tests.

\section{Numerical application}

\subsection{Cohesive soil Deposits}

To illustrate the effects that overconsolidation ratios $O C R$ have on surface seismic response, a generalized typical layered soil/rock model is considered in this section. The soil deposit is assumed to be a clay layered profile, with a thickness of $36 \mathrm{~m}$ over the bedrock. The shear wave velocity profile is shown in figure 18 . The shear wave velocity profile gives an average shear wave velocity in the upper $30 \mathrm{~m}\left(V_{s} 30\right)$ of $200 \mathrm{~m} / \mathrm{s}$, corresponding to a site category $\mathrm{C}$ of Eurocode8. The fundamental elastic period of the soil profile is $0.67 \mathrm{~s}$. 


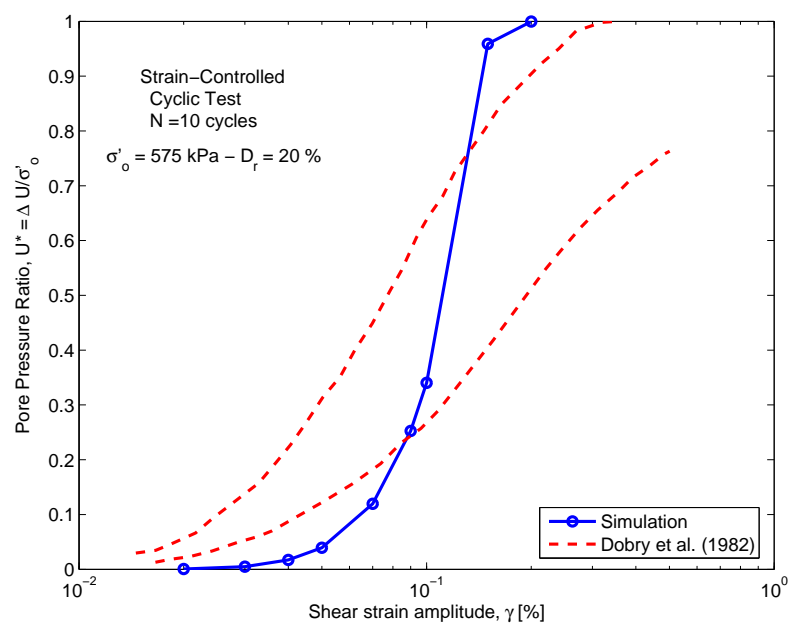

Figure 17. Simulated $D_{r}=20 \%$ sand model liquefaction curves, strain controlled tests.

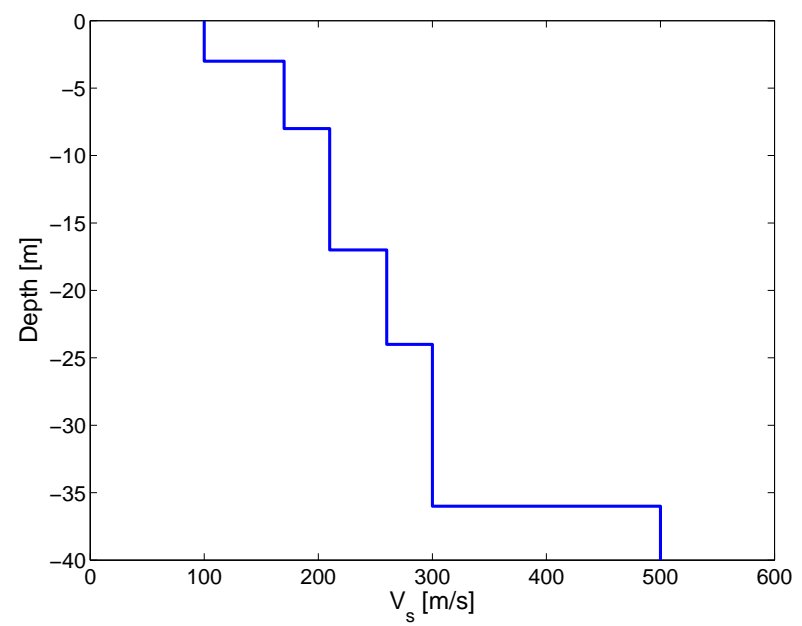

Figure 18. Soil profile characterization.

The profile is composed of clays with $I_{p}$ equal to $15 \%$. The soil profile is considered homogeneous and three different $O C R$ values (i.e. 1.0, 2.0 and 3.0) are used. Even if the $V_{s}$ value used for the three cases is the same, only the initial state $(O C R)$ is changed in order to illustrate its influence on the seismic response of the profile.

A deformable bedrock with a shear wave velocity of $500 \mathrm{~m} / \mathrm{s}$ is placed at $36 m$ depth. 
The methodology explained in this paper is used to determine the soil model parameters. In this case, the Darendeli (2001) curves for $I_{p}=15 \%$ clay have been used as "measured" curves.

Figure 19 shows the model prediction for the variation of $G / G_{\max }$ with the cyclic shear strain $\gamma$ in undrained strain-controlled cyclic direct simple shear tests at two initial confining pressures $\left(\sigma_{o}^{\prime}=25\right.$ and $100 \mathrm{kPa}$ ). These curves are compared with the modulus reduction curve given by Darendeli (2001) for $I_{p}=15 \%$ clay.

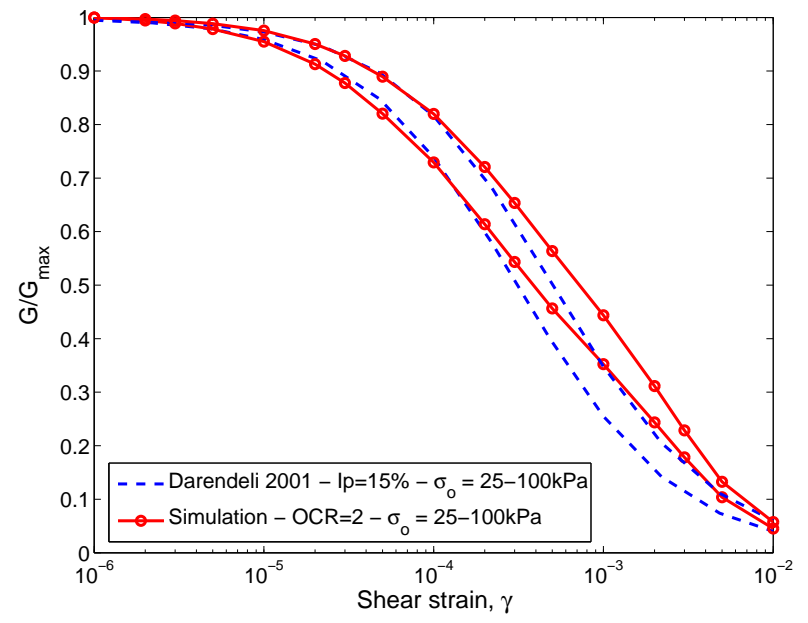

Figure 19. Comparison between simulated $G / G_{\max }-\gamma$ and Darendeli (2001) reference curves for $I_{p}=15 \%$ clay model

The used seismic input motions are the acceleration records of Friuli earthquake - San-Rocco site (Italy-1976) and Superstition Hills earthquake - Supers. Mountain site (USA-1987). These signals are consistent with the response spectra of Type A soil (i.e. rock) of Eurocode8. The response of the site profile is computed using only the horizontal component of the input records.

In as far as it concerns the acceleration history obtained in our analyses, the effect of the $O C R$ value of the soil profile on the obtained acceleration at the surface level $\left(P G A_{\text {surf }}\right)$ is studied.

In practice, the most common approach to estimate the $P G A_{\text {surf }}$ value is to use attenuation relationships such as those given by Idriss (1991) or Dickenson and Seed (1996). These relations take into account the influence of the non linearity of soil behaviour on the obtained $P G A_{\text {surf }}$ value. Figure 20 shows the variation of peak ground acceleration at the surface $\left(P G A_{\text {surf }}\right)$ as a function of the maximum acceleration at the outcropping bedrock $\left(a_{\max }\right.$ out $)$. According to this figure, the amplification of peak ground acceleration on the ground sur- 


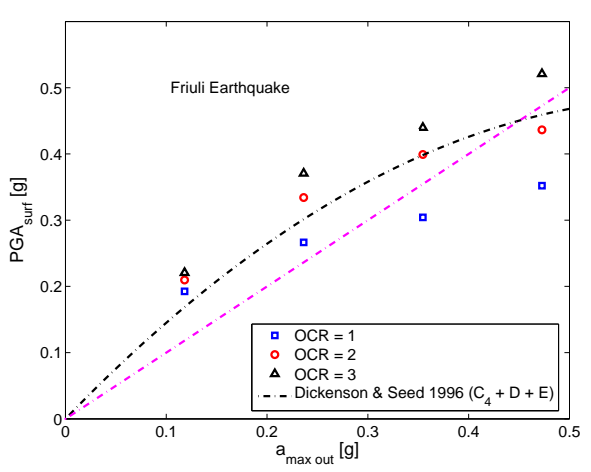

a.

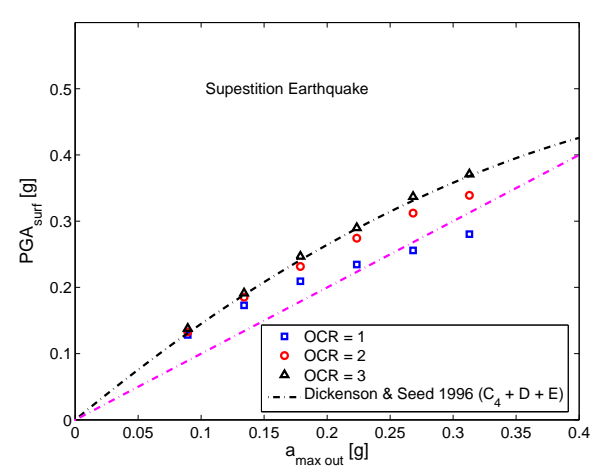

b.

Figure 20. Relationships between maximum acceleration on bedrock and surface obtained in the soil profile for different earthquakes : a) Friuli earthquake and b) Superstition earthquake.

face relative to bedrock appears for $a_{\max }$ out value to be less than $0.25 \mathrm{~g}$ in the case of normally consolidated soil behaviour (i.e. $O C R=1$ ). Furthermore, these responses illustrate that the estimated $P G A_{\text {surf }}$ values for the model with $O C R=1$ are much smaller than those obtained for $O C R=2$ and 3 .

This variation is due to the difference in the "rigid" behaviour of overconsolidated soils even if the $V_{s}$ profiles and $G / G_{\max }-\gamma$ curves are similar.

\section{Conclusions}

A consistent and coherent methodology to determine an elastoplastic model parameters for clayey and sandy soils has been proposed. For clays, Atterberg limits and an $O C R$ ratio can be used to identify the mechanical parameters, while for sands, the relative density or the void ratio is the dominant parameter.

This methodology, which can form the basis for a decision making process, has two aims. First, to give a handy, easy-to-obtain and coherent set of parameters to use when no experimental data is available. Second, to be used as the starting point for cases where geotechnical measurements are not sufficient.

In the numerical applications, the importance of all model parameters and the differences that the errors on their identification can induce in the seismic site response were illustrated. 
In the companion paper, this methodology is generalised to natural soil in order to evaluate the seismic response of real sites subjected to natural acceleration records.

\section{Acknowledgements}

A part of this study has been done in the framework of the European Community Contract No ENV-CT97-0392.

\section{References}

Anastasiadis, J. A. and K. D. Pitilakis. Shear modulus $\mathrm{G}_{o}$ and damping of typical Greek soils at low strain amplitudes. Technika Chronika, Scien. J. of TCG, 16(3):9-18, 1996.

Aubry, D., J.-C. Hujeux, F. Lassoudire and Y. Meimon. A double memory model with multiple mechanisms for cyclic soil behaviour. Proceedings of the Int. Symp. Num. Mod. Geomech, Balkema, 3-13,1982.

Aubry, D., A. Modaressi and H. Modaressi. A constitutive model for cyclic behaviour of interfaces with variable dilatancy. Computers and Geotechnics,9(1/2):4758,1990 .

Bardet, J.-P. Experimental Soil Mechanics. Prentice Hall, Upper Saddle River,NJ, 1997.

Been, K. and M. G. Jefferies. A state parameter for sands Géotechnique, 35(2), 99-112, 1985.

Biarez, J. and J.-L. Favre. Corrélations de paramètres en mécanique des sols. Ecole Centrale Paris, Table ronde nationale, 1972.

Biarez, J. and P.-Y. Hicher. Elementary Mechanics of Soil Behaviour, Saturated and Remolded Soils. Balkema, Amsterdam, Netherlands, 1994.

Darendeli, M. B. Development of a new family of normalized modulus reduction and material damping curves. Ph.D. Dissertation, University of Texas at Austin, USA, 2001.

Dickenson, S. E. and R. B. Seed. Non-linear Dynamic Response of Soft and Deep Cohesive Soil Deposits. Proceedings of the International Workshop on Site Response Subjected to Strong Earthquake Motions, Vol. 2. pp. 67-81, Yokosuka, Japan, 1996.

Dobry, R., R. S. Ladd, F. Y. Yokel, R. M. Chung and D. Powell. Prediction of pore water pressure buildup and liquefaction of sands during earthquakes by the cyclic strain method. National Bureau of Standards, Building Science Series 138, 1982.

Favre, J.-L. Milieu continu et milieu discontinu: mesure statistique indirecte des paramètres rhéologiques et approche probabiliste de la sécurité. Thèse de docteur ès sciences, Univ. Pierre et Marie Curie, Paris VI, France, 1980.

Ghaboussi, J. and S. U. Dikmen. Liquefaction analysis of horizontally layered sands. Journal of Geotechnical Engineering Division - ASCE, 104(nr GT3), 341-356, 1978. 
Hardin, B. O. The nature of stress-strain behavior for soils. In Proceedings ASCE Geotechnical Engineering Division. Specially Conference On Earthquake engineering and Soil Dynamics, Pasadena, CA, Vol. 1, pp. 3-89, 1978.

Hicher, P.-Y. and A. Rahma. Micro-macro correlations for granular media. Application to the modelling of sands. European Journal of Mechanics. A/Solids, 13(6), 763-781, 1994.

Hujeux, J.-C. Une loi de comportement pour le chargement cyclique des sols. In V. Davidovici, editor, Génie Parasismique, Presses ENPC, France, pp. 278-302, 1985.

Idriss, I. M. Earthquake ground motions at soft soil sites. 2nd International Conference on recent Advances in Geotechnical Earthquake Engineering and Soil Dynamics, Vol. 3. pp. 2265-2271, St. Louis, Missouri. Eds. Prakash, 1991.

Ishibashi, I. and X. Zhang. Unified dynamic shear moduli and damping ratios of sand and clay. Soils and Foundations, 33(1), 182-191, 1993.

Ishihara, K. Liquefaction and flow failure during earthquakes. 33rd Rankine lecture. Géotechnique, 43(3), 351-415, 1993.

Ishihara, K., F. Tatsuoka and S. Yasuda. Undrained deformation and liquefaction of sand under cyclic stresses. Soils and Foundations, 15(1), 29-44, 1975.

Iwasaki, T., F. Tatsuoka and Y. Takagi. Shear moduli of sands under cyclic torsional shear loading. Soils and Foundations 18(1), 39-56, 1978.

Jamiolkowski, M., C. C. Ladd, J. T. Germaine and R. Lancellotta. New developments in field and laboratory testing of soils. In Proceedings 11th International Conference On Soil Mechanics and Foundations Engineering, San Francisco, CA, Vol. 1, pp 57-154, 1985.

Kallioglou, P., Th. Tika and K. Pitilakis. Dynamic characteristics of natural cohesive soils. In Proceedings 2nd International Conference On Earthquake Geotechnical Engineering, Lisbon, Portugal, 1999.

Kohata, Y., F. Tatsuoka, L. Wang, G. L. Jiang, E. Hoque and T. Kodaka. Modelling the non-linear deformation properties of stiff geomaterials. Symposium In Print. Géotechnique, 47(3), 563-580, 1997.

Kokusho, T. Cyclic triaxial test of dynamic soil properties for wide strain range. Soils and Foundations, 20(4), 45-60, 1980.

Kokusho, T., Y. Yoshida and Y. Esashi. Dynamic properties of soft clays for wide strain range. Soils and Foundations, 22(4), 1-18, 1982.

Kramer, S. L. Geotechnical Earthquake Engineering. Prentice Hall, Upper Saddle River, NJ, 1996.

Mellal, A. Analyse des effets du comportement non linéaire des sols sur le mouvement sismique. Thèse de doctorat, École Centrale Paris, France, 1997.

Modaressi, H. and E. Foerster. CyberQuake. User's manual, BRGM, France, 2000.

Pande, G. N. and S. Pietruszczak. A critical look at constitutive models for soils. In R. Dungar and J.A. Studer, editors, Geomechanical modelling in engineering practice, A.A. Balkema, Rotterdam, The Netherlands, pp. 369-395, 1986.

Prévost, J.-H. and K. Hoeg. Effective stress-strain strength model for soils. Journal of Geotechnical Engineering Division - ASCE, 101(nr GT3), 259-278, 1975.

Saim, R. Dès comportements repères des grains sans colle à un exemple de sol réel. Thèse de doctorat, École Centrale Paris, France, 1997.

Santos, J. A. Caracterização de solos através de ensaios dinâmicos e cíclicos de torção ; Aplicação ao estudo do comportamento de estacas sob acções horizontais estáticas e dinâmicas. Dissertação Doutor, Universidade Técnica de Lisboa, Instituto Superior Técnico, Portugal, 1999. 
Schofield, A. N. and C. P. Wroth. Critical State Soil Mechanics, McGraw-Hill, London, 1968.

Seed, H. B. and I. M. Idriss. Soil moduli and damping factors for dynamic response analyses. University of California, Berkeley, CA, Report EERC-70-10, Earthquake Engineering Research Center, 1970.

Seed, H. B., R. T. Wong, I. M. Idriss and K. Tokimatsu. Moduli and damping factors for dynamic analyses of cohesionless soils. Journal of Geotechnical Engineering - ASCE, 112(11), 1016-1032, 1986.

Sun, J. I., R. Golesorkhi and H. B. Seed. Dynamic moduli and damping ratios for cohesive soils. University of California, Berkeley, CA, EERC-88-15, 1988.

Vucetic, M. Cyclic threshold shear strains in soils. Journal of Geotechnical Engineering - ASCE, 120(12), 2208-2228, 1994.

Vucetic, M. and R. Dobry. Effect of soil plasticity on cyclic response. Journal of Geotechnical Engineering - ASCE, 117(1), 89-107, 1991. 